\title{
Definition of South China Sea Monsoon Onset and Commencement of the East Asia Summer Monsoon*
}

\author{
B. WANG \\ Department of Meteorology and International Pacific Research Center, University of Hawaii at Manoa, Honolulu, Hawaii \\ LiNHo \\ Department of Atmospheric Sciences, National Taiwan University, Taipei, Taiwan \\ YONGSHENG ZHANG \\ International Pacific Research Center, University of Hawaii at Manoa, Honolulu, Hawaii \\ M.-M. LU \\ Central Weather Bureau, Taipei, Taiwan
}

(Manuscript received 13 November 2002, in final form 1 April 2003)

\section{ABSTRACT}

\begin{abstract}
The climatological mean summer monsoon onset in the South China Sea (SCS) is a remarkably abrupt event. However, defining onset dates for individual years is noticeably controversial. The controversies and complications arise primarily from a number of factors: the intermittent southward intrusion of cold fronts into the northern SCS, the bogus onset in late April before the establishment of tropical monsoons over Indochina, and active intraseasonal oscillation. In this paper, a simple yet effective index, $U_{\mathrm{SCS}}$, the 850 -hPa zonal winds averaged over the central SCS $\left(5^{\circ}-15^{\circ} \mathrm{N}\right.$ and $\left.110^{\circ}-120^{\circ} \mathrm{E}\right)$, is proposed for objectively defining the SCS monsoon onset. This onset index depicts not only the sudden establishment of the tropical southwesterly monsoon over the SCS but also the outbreak of the rainy season in the central-northern SCS.

In this paper the East Asian summer monsoon (EASM) is defined as the broadscale summer monsoon over East Asia and the western North Pacific region $\left(0^{\circ}-40^{\circ} \mathrm{N}, 100^{\circ}-140^{\circ} \mathrm{E}\right)$. It is shown that the seasonal transition of EASM can be objectively determined by the principal component of the dominant empirical orthogonal mode of the $850-\mathrm{hPa}$ zonal winds, $U_{\mathrm{EOF} 1}$. It is found that the local index $U_{\mathrm{SCS}}$ represents $U_{\mathrm{EOF} 1}$ extremely well; thus, it can be used to determine both the SCS onset and the commencement of the broadscale EASM. The result suggests that the SCS summer monsoon onset indeed signifies the beginning of the summer monsoon over East Asia and the adjacent western Pacific Ocean. Evidence is also provided to show the linkage between the two salient phases of EASM: the local onset of the SCS monsoon and the local onset of the mei-yu (the rainy season in the Yangtze River and Huai River basin and southern Japan).
\end{abstract}

\section{Introduction}

A unique feature of the South China Sea (SCS) summer monsoon (SCSSM) is the simultaneous commencement across its large latitudinal range from $3^{\circ}$ to $22^{\circ} \mathrm{N}$ (Fig. 1a). In contrast to the relatively "punctual" onset of the Indian summer monsoon at Kerala, the onset of

* School of Ocean and Earth Science and Technology Publication Number 6239 and International Pacific Research Center Contribution Number 227.

Corresponding author address: Dr. B. Wang, Dept. of Meteorology and International Pacific Research Center, University of Hawaii at Manoa, 2525 Correa Rd., Honolulu, HI 96822.

E-mail: bwang@soest.hawaii.edu the SCSSM exhibits considerable year-to-year variation (Wu and Wang 2001). The SCSSM onset has been considered as a precursor to East Asian summer monsoon (EASM) development (Tao and Chen 1987; Lau and Yang 1997). Study of the SCSSM onset has important ramifications for understanding Asian monsoon variability.

Defining the onset date of the SCSSM for an individual year has been noticeably controversial, even though the corresponding climatological mean onset is a notable singular episode (e.g., Wang and Xu 1997; LinHo and Wang 2002). The lack of a universally accepted definition of SCSSM onset is a major roadblock for studying interannual variability of the monsoon evolution. 


\section{a) $850 \mathrm{hPo}$ Wind $1979-2001$}

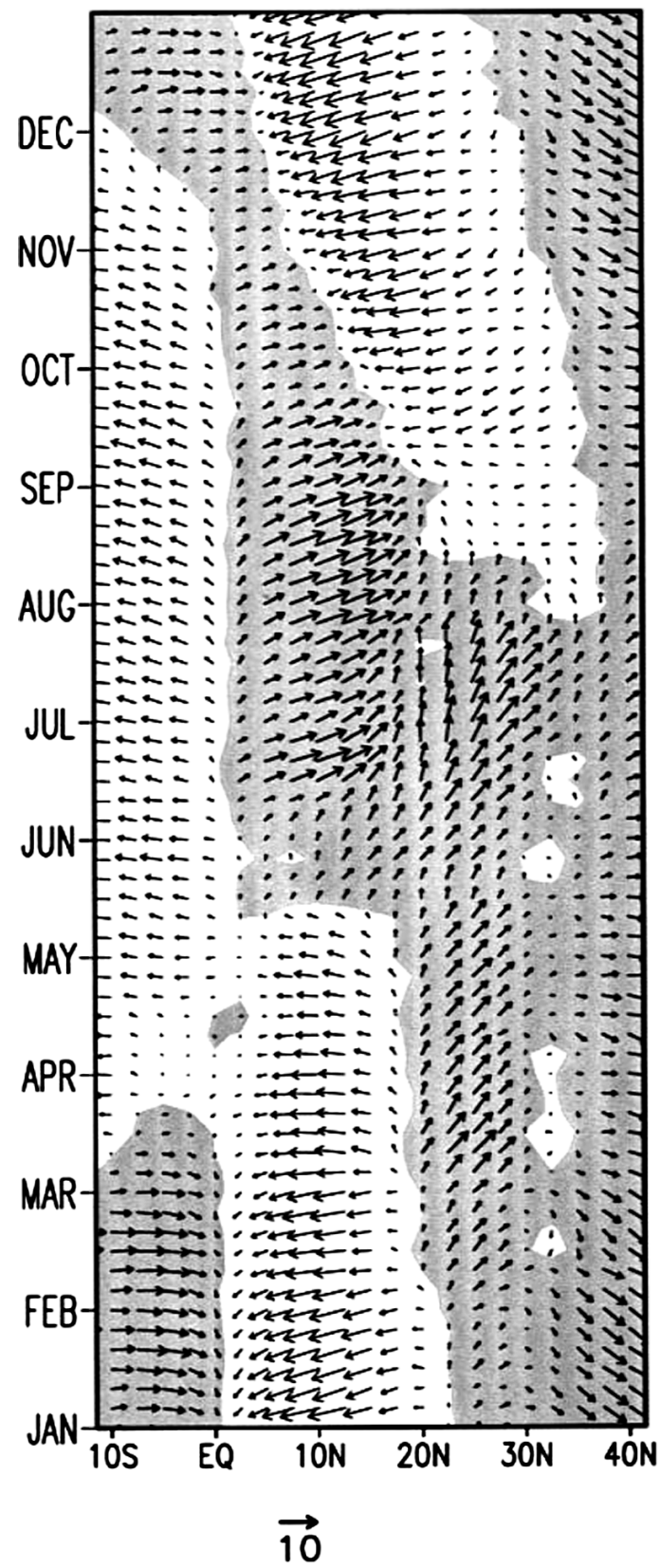

b) CMAP roinfoll $1979-2001$

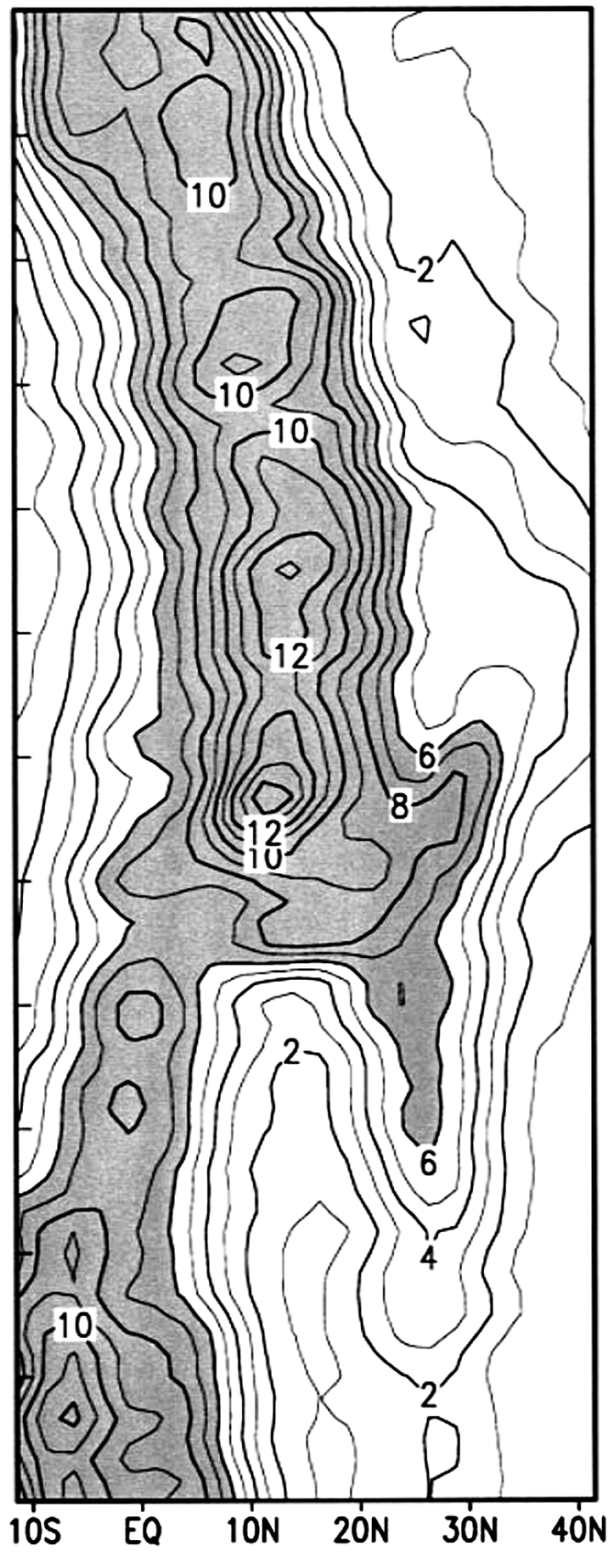

FIG. 1. Time-latitude distribution of the (a) climatological pentad mean 850-hPa zonal winds and (b) CMAP pentad mean rainfall. The data are averaged over the longitude bands between $110^{\circ}$ and $120^{\circ} \mathrm{E}$ across the SCS. The climatology was made using data from 1979 to 2001. The shading in (a) indicates winds having a westerly component. The shading in (b) denotes precipitation rate exceeding $6 \mathrm{~mm}^{\text {day }}{ }^{-1}$.

A great variety of local indices with objective or subjective criteria have been proposed to define the onset of SCSSM. These indices include precipitation or its proxies: outgoing longwave radiation (OLR), upper-tropospheric water vapor brightness temperature, high cloud amount, highly reflective cloud (Tanaka 1992; Chen et al. 1996; Yan 1997; Lin and Lin 1997; Zhu et al. 2001), low-level or surface winds (Yan 1997; Zhang et al. 2001), low-level relative vorticity ( $\mathrm{Lu}$ et al. 2000), low-level meridional winds (Lu and Chan 1999), equivalent potential temperature (Gao et al. 2001), vertical zonal wind shear ( $\mathrm{Li}$ and $\mathrm{Wu} 2000$ ), differential geopotential heights (He et al. 2001), or combined measures of convection and low-level winds (Wang and Wu 1997; May 1997; Xie et al. 1998; Liang et al. 1999; Kueh and Lin 2001). Some of these local indices were combined 
TABLE 1. List of major previous studies that have provided a definition for the onset of the SCSSM. Here, GMS = Geostationary Meteorological Satellite, TBB = brightness temperature, GPI = GOES (Geostationary Operational Environmental Satellite) Precipitation Index, NMC $=$ National Meteorological Center, NOAA $=$ National Oceanic and Atmospheric Administration, NASA/DAO $=$ National Aeronautics and Space Administration Data Assimilation Office, and HRC = Hydrologic Research Center.

\begin{tabular}{lll}
\hline \hline \multicolumn{1}{c}{ Authors } & \multicolumn{1}{c}{ Defining variable and/or method } & Data period \\
\hline Hsu et al. (1999) & Wind (850 hPa); subjective & ECMWF (1986-96); OLR (1975-92) \\
Wang and Wu (1997) & Zonal wind and OLR; criteria & ECMWF (1979-92); OLR (1975-92) \\
Xie et al. (1998) & OLR and wind (850 hPa); criteria & OLR (1979-94); NMC (1979-94) \\
Lin and Lin (1997) & TBB and ECMWF; subjective & GMS TBB (1980-91); ECMWF (1985-91) \\
Chen et al. (1996) & TBB, wind; criteria & GMS TBB (1980-91); and OLR (1979-88) \\
May (1997) & Wind, OLR; subjective & ECMWF (1985-93); OLR (1985-93) \\
Hsu et al. (1999) & Streamfunction EOF analysis; criteria & ECMWF (1979-93); OLR (1979-93) \\
Yan (1997) & Wind; criteria & NCEP-NCAR (1979-95); OLR \\
Kueh and Lin (2001) & Wind and OLR; subjective & NCEP-NCAR reanalysis (1958-97) \\
Gao et al. (2001) & Zonal wind and $\theta_{\text {se }}$ (850 hPa); criteria & NCEP-NCAR reanalysis (1958-99) \\
Lu et al. (2000) & 850-hPa relative vorticity; criteria & NOAA GPI, NASA/DAO reanalysis \\
Lau and Yang (1997) & GPI EOF analysis & ECMWF (1981-86) \\
Chang and Chen (1995) & Wind and convection; subjective analysis & NCEP-NCAR reanalysis (1953-99) \\
Zhang et al. (2001) & Zonal wind (850 hPa); criteria & NCEP-NCAR (1951-99) \\
Qian and Yang (2000) & Precipitation, TBB, OLR, wind (850 hPa); criteria & 1978-89 \\
Liang et al. (1999) & Wind (850 hPa); criteria plus subjective analysis & \\
Tanaka (1992) & GMS high-cloud amount &
\end{tabular}

with a subjective analysis of the large-scale seasonal transition or low-frequency oscillation modes (Chang and Chen 1995; Hwu et al. 1998; May 1997; Kueh and Lin 2001). There are also definitions that are derived from objective analyses of the seasonal transition of the large-scale circulation over Asia or Southeast Asia (Hsu et al. 1999; Lau and Yang 1997).

The resulting onset dates for some years are remarkably diverse because the definitions are sensitive to the choices of local variables or circulation systems and to the ways their variations are measured. Kueh and Lin (2001) compared monsoon onset dates determined by nine definitions for the period 1979-95. There were 7 years during which different definitions yield similar onset dates, whereas in the other 10 years $(1981,1982$, $1983,1984,1985,1987,1992,1993,1994,1995)$ the onset dates vary by more than three pentads. Zhou et al. (2001) made another comparison of eight different definitions for the 40-yr period 1958-97. There were 16 years during which the onset pentads showed major differences. Identifying the onset dates for those years is a challenging task. The controversies arise from the fact that the SCS monsoon advances with a wide variety of synoptic and intraseasonal fluctuations and spatial variability in strength. To the authors' knowledge, about 20 different definitions have been proposed. A summary of the relevant studies on the definition of SCSSM onset is presented in Table 1.

It is imperative to establish a universally accepted definition of the SCSSM onset. A reliable determination of the onset date for each individual year is indispensable for forming a basis to study further the interannual variability of the monsoon onset and strength. The monsoon community needs compelling principles and a generally recognized framework for establishing objective and rational criteria for defining the SCSSM onset. This is the primary objective of the present study. Section 3 will discuss the meteorological principles for objectively determining the SCS monsoon onset, which lead to a simple yet effective definition.

In this paper the SCS summer monsoon is perceived as a critical componet of the East Asia summer monsoon. Concerning the terminology of the East Asia monsoon, so far there is no generally accepted definition. From a geographical point of view, however, there are two definitions. The first is a more localized definition that refers to a subtropical monsoon confined in the region $20^{\circ}-40^{\circ} \mathrm{N}, 100^{\circ}-140^{\circ} \mathrm{E}$ (e.g., Zhang et al. 1996). The second invokes a broadscale definition, which includes the subtropical monsoon front, the western North Pacific (WNP) subtropical high, and the tropical WNP monsoon trough (Tao and Chen 1987). Therefore, a broader view of the East Asian monsoon system includes both the WNP tropical monsoon and the subtropical monsoon. The second definition covers roughly the region from $0^{\circ}$ to $40^{\circ} \mathrm{N}$ and from $100^{\circ}$ to $140^{\circ} \mathrm{E}$. In this paper, we delineate the EASM as the summer monsoon in East Asia (EA) and the WNP region $\left(0^{\circ}-40^{\circ} \mathrm{N}\right.$, $\left.100^{\circ}-140^{\circ} \mathrm{E}\right)$.

Our objective further extends to exploring the linkage of the SCSSM onset to the development of the EASM. Chen et al. (2001) proposed a two-stage rainy season onset over East Asia. The first stage occurs in spring over south China (preflood period); the second stage occurs over the Yangtze River valley in June after the onset of the tropical monsoon over the SCS. SCSSM onset has been regarded as the start of the EASM largely because some believe that the SCSSM onset is the earliest onset over East Asia (Tao and Chen 1987; Lau and Yang 1997) or South Asia (Chang and Chen 1995). However, recent studies have challenged this notion. It has been shown that the summer monsoon starts over the southeast Bay of Bengal and Indochina Peninsula about 10-15 days before the onset over the SCS (Wang 
1994; He et al. 1996; Wu and Zhang 1998; Wang and Qian 2000; Qian and Yang 2000; Xu et al. 2001; Wang and LinHo 2002).

As far as the onset of East Asian summer monsoon is concerned, there also exist two points of view. Tao et al. (1983) defines the occurrence of the rainbelt over the Yangtze River valley as the onset of the EASM. This is consistent with the notion of subtropical monsoon. In section 4, we will discuss how to determine the large-scale onset of the broadscale EASM. We will show evidence that the local SCSSM onset can faithfully indicate the inception of the broadscale EASM, while the mei-yu is the second salient phase of the broadscale EASM onset.

\section{Data}

One of the difficulties in studying monsoon onset over the ocean is the lack of observations. In the data-void marine environment, one has to primarily rely on the satellite estimation of rainfall and circulations produced by data assimilation systems that incorporate satelliteobserved winds and ship observations.

The circulation data used in the present analysis are derived from a 54-yr (1948-2001) National Centers for Environmental Prediction-National Center for Atmospheric Research (NCEP-NCAR) reanalysis (Kalnay et al. 1996). Daily mean and 5-day mean wind data on $2.5^{\circ} \times 2.5^{\circ}$ grids are used. The quality of the $850-\mathrm{hPa}$ reanalysis winds over the SCS are more reliable than other fields due to plentiful ship observations along ship tracks in the South China Sea and the introduction of satellite cloud wind observations after the late 1970s. The 54-yr data set is inhomogeneous in time. We have to bear this inhomogenity in mind and apply these data with caution. The data before 1958 are less reliable due in part to the lack of ship observations throughout the Philippine Sea prior to the late 1950s (Wang 1995).

The primary precipitation data analyzed in this study are the Climate Prediction Center Merged Analysis of Precipitation (CMAP; Xie and Arkin 1997) data that were derived by merging rain gauge observations, microwave and infrared satellite images, and numerical model outputs. The pentad mean CMAP rainfall data cover the period January 1979 to December 2001 with a global coverage on $2.5^{\circ} \times 2.5^{\circ}$ grids. Over the ocean, the accuracy and reliability of the pentad mean CMAP on small spatial scales has not been fully determined because of the lack of ground truth observations. However, since the CMAP data were based on merged multisource estimates, the uncertainties contained in each individual estimate are reduced. Given the weaknesses of all the available rainfall datasets, information about oceanic regions derived from the CMAP analysis should be viewed as preliminary and should be updated when more accurate data become available. It is also critical to search for physically consistent patterns between the
850-hPa winds and rainfall, which can add confidence to the analyses.

\section{A local definition of SCS summer monsoon onset}

In view of the complex nature of the monsoon phenomena, to define local SCS monsoon onset objectively and succinctly, one needs to address the following questions:

- What meteorological variable, and in what domain, best represents the summer monsoon onset over the SCS?

- To what degree does the chosen indicator reflect both the characteristic changes in precipitation and circulation patterns during the SCSSM onset?

- What succinct criteria can be proposed so that the SCSSM onset can be objectively determined?

- To what extent does the chosen indicator reflect the seasonal transition of the monsoon circulations over a larger domain including and beyond the SCS?

\section{a. Choice of the defining variables and the definition domain}

The monsoon onset can be determined by the seasonal change in either surface winds or local rainfall since the monsoon climate is characterized by an annual reversal of the winds and by a contrast between an intense rainy summer and a dry winter. In some monsoon regions, however, the start of the local rainy season does not necessarily coincide with the date of seasonal reversal of the local surface winds. In these regions, it is impossible to use both fields to describe monsoon commencement.

Since the late arrival of monsoon rain can be disastrous for agriculture and the economy, the beginning of the rainy season is often viewed as the onset of the summer monsoon. For instance, the monsoon onset in India is represented by the beginning of the rainy season over the Kerala (Ananthankrishnan and Soman 1988; Soman and Kumar 1993).

Examination of the climatological mean onset features may offer useful hints for determining what meteorological variable, and in what domain, best represents the SCSSM onset. This is because the mean onset of the SCSSM plays a unique role in the evolution of the Asian summer monsoon.

Figure 1a displays latitudinal variations of the 850$\mathrm{hPa}$ zonal wind averaged between $110^{\circ}$ and $120^{\circ} \mathrm{E}$. A striking change in the wind from an easterly to a westerly regime occurs on Julian pentad 28 (P28; 16-20 May), which denotes the onset of the mean SCSSM. Note that the reversal of the zonal wind direction is primarily confined to the latitudinal bands between $5^{\circ}$ and $15^{\circ} \mathrm{N}$. This latitudinal band covers the central SCS. The results shown in Fig. 1a suggest that the $850-\mathrm{hPa}$ 
zonal winds averaged over the region $5^{\circ}-15^{\circ} \mathrm{N}, 110^{\circ}-$ $120^{\circ} \mathrm{E}$ (the precise domain is $3.75^{\circ}-16.25^{\circ} \mathrm{N}, 108.75^{\circ}-$ $121.25^{\circ} \mathrm{E}$ ) can be used as a wind index to quantify SCS circulation change before, during, and after the monsoon onset. This wind index will be denoted by $U_{\mathrm{sCS}}$.

Concurrent with the reversal of the $850-\mathrm{hPa}$ zonal winds, there is a sharp increase in rainfall over the SCS in the latitudinal band between $10^{\circ}$ and $20^{\circ} \mathrm{N}$ (Fig. 1b). Thus, a rainfall index, which is the rainfall rate averaged over the region $10^{\circ}-20^{\circ} \mathrm{N}, 110^{\circ}-120^{\circ} \mathrm{E}$, can also be constructed to describe the SCS rainy season onset.

\section{b. Coherency between the 850-hPa westerly wind index and the rainfall index}

The domain in which the rainfall index is defined is about $5^{\circ}$ latitude north of the corresponding domain for $U_{\mathrm{sCS}}$. This spatial phase relationship between convection and the westerly index is consistent with our understanding of the interaction between tropical convection and the low-level circulation. On the one hand, convection, which tends to overlay the maximum low-level cyclonic vorticity and associated boundary layer convergence, normally occurs to the north of the maximum westerlies. On the other hand, precipitation-induced condensational latent heating generates ascending Rossby waves propagating westward, which enhances westerlies to the south and southwest of the maximum convection.

The above theoretical interpretation can be verified by an empirical relationship between the $850-\mathrm{hPa}$ zonal wind and the precipitation distribution. Figure $2 \mathrm{a}$ shows correlation coefficients of the $850-\mathrm{hPa}$ zonal wind $\left(U_{850}\right)$ at each grid point with reference to the SCS rainfall index for the period from pentad 20 (11-20 April) to 37 (4 July-30 June) of each year from 1979 to 2001. The best correlation between the westerly and the SCS rainfall index is found in the central SCS in the region $\left(5^{\circ}-15^{\circ} \mathrm{N}, 110^{\circ}-120^{\circ} \mathrm{E}\right)$ where the correlation coefficients exceeds 0.7 for a sample size of 414 . Figure $2 b$ shows the correlation coefficients of the rainfall rate at each grid point with reference to the $U_{\mathrm{SCS}}$. Obviously, the best positive correlation of rainfall with $U_{\mathrm{SCS}}$ is located in the region $10^{\circ}-20^{\circ} \mathrm{N}, 110^{\circ}-120^{\circ} \mathrm{E}$ where the rainfall best characterizes the SCS rainy season onset. The results shown in Figs. $2 \mathrm{a}$ and $2 \mathrm{~b}$ indicate that the westerly index $U_{\mathrm{SCS}}$ can well represent the rainfall index.

We choose $U_{\mathrm{SCS}}$ to define the SCSSM onset, because it is an effective indicator for both the circulation and rainfall variability. There are several reasons for this choice of the wind index. First, long meteorological records for $U_{850}$ are available (1948-2001) from which it is easy to prepare 5-day normal $U_{\mathrm{SCS}}$. The rainfall data (e.g., CMAP) have a substantially shorter record (1979-2001). Second, the ship observations over the SCS and the observed satellite cloud winds after 1970 significantly enhance the reliability of the $850-\mathrm{hPa}$ winds over the SCS, while the accuracy of the rainfall (a)

Corr. of u850 with reference to Rainfall over (10-20N,110-120E)

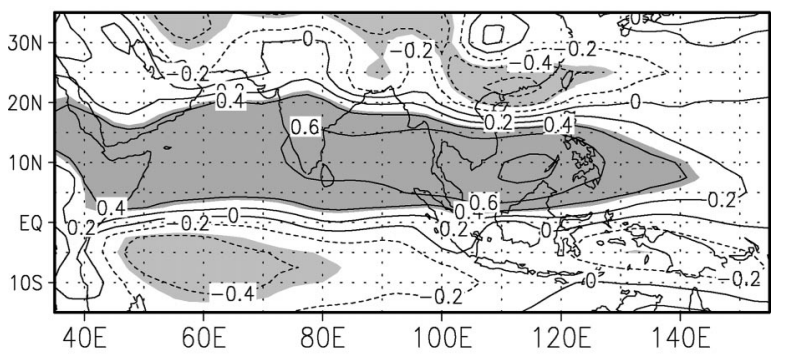

(b)

Corr. of Rainfall with reference to 4850 over $(5-15 N, 110-120 \mathrm{E})$

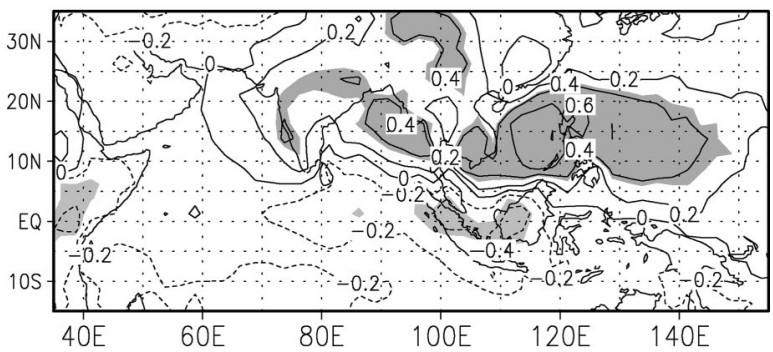

FIG. 2. (a) Correlation map of the $850-\mathrm{hPa}$ zonal wind with respect to the SCS rainfall index, which is the CMAP rainfall averaged over $10^{\circ}-20^{\circ} \mathrm{N}, 110^{\circ}-120^{\circ} \mathrm{E}$. (b) Correlation map of the pentad rainfall rate with regard to the 850 -hPa zonal winds index with the zonal winds averaged over $5^{\circ}-15^{\circ} \mathrm{N}, 100^{\circ}-120^{\circ} \mathrm{E}$. The contour interval is 0.1 . The data used are the pentad mean CMAP rainfall and pentad mean U850 ranging from pentad 20 (6-10 Apr) to pentad 37 (30 Jun-4 Jul) for each year and for the period 1979-2001. Shading indicates areas where the correlation coefficients are statistically significant at the $95 \%$ confidence level.

estimated by satellite observations is limited by their less frequent sampling and uncertainties in the data retrieval. Third, and perhaps the most significant, compared with the rainfall, the low-level winds reflect more pertinent large-scale variations, while rainfall is susceptible to influences of small-scale circulation systems and local factors. In addition, as will be demonstrated in the next section, the $U_{\mathrm{SCS}}$ is highly indicative of the seasonal transition of the large-scale circulation.

\section{c. Objective criteria for defining the onset pentad}

To derive objective criteria, we examine the pentad ( 5 day) mean time series presented in the left panel of Table 2. In about $80 \%$ of the years examined (43 out of a total $54 \mathrm{yr}$ ), the SCSSM onsets are characterized by an obvious shift from a steady easterly to a steady westerly regime. For these $43 \mathrm{yr}$, the onset pentad can be readily determined without ambiguity. However, in the remaining $11 \mathrm{yr}$, the regime shift was obscured by either a vigorous intraseasonal oscillation (1951, 1980, 1989, and 1996) or a flat transition phase during which $U_{\text {SCS }}$ fluctuates around zero $(1952,1956,1968,1971$, 1984, 1992, and 1994). The latter case is referred to as 
TABLE 2. (left) Digitized time series of the SCSSM onset index, $U_{\text {scs }}$, from P24 to P35 (26 Apr to 24 Jun) for each year from 1948 to 2001. The $U_{\text {scs }}$ is the 850 -hPa zonal wind averaged over $5^{\circ}-15^{\circ} \mathrm{N}, 100^{\circ}-120^{\circ} \mathrm{E}$. Shaded boxes indicate the onset pentad for the SCSSM defined in this paper. The last row shows DU, the change of $U_{\text {scs }}$ across the onset as described in the text. The lightface (boldface) numbers represent easterlies (westerlies). (right) The same as in the left panel except for the EASM onset index, which is defined by the principal component of the first EOF mode of the $850-\mathrm{hPa}$ zonal winds in the domain $0^{\circ}-40^{\circ} \mathrm{N}, 100^{\circ}-140^{\circ} \mathrm{E}$. The shaded boxes denote the onset pentad for the EASM.

$$
\text { Zonal Wind }(110-120 \mathrm{E}, 5-15 \mathrm{~N})
$$

EOF1 of Zonal Wind

\begin{tabular}{|c|c|c|c|c|c|c|c|c|c|c|c|c|c|c|c|c|c|c|c|c|c|c|c|c|c|}
\hline & & & & & & & & & & & & & & & & & & & & 30 & & 32 & & & 35 \\
\hline & & & 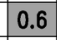 & 3.2 & .3 & .7 & 8.7 & .4 & 7.9 & 5.9 & 6.0 & 8.0 & 9.2 & .8 & 1.3 & .2 & 2.2 & 8 & 1.9 & 6.2 & 8.8 & 5.9 & .8 & 3.2 & 5.7 \\
\hline & & & & & & & 0.4 & & 4.5 & & 3 & & 1 & .4 & .0 & .6 & 8 & & 0.7 & & 3.4 & .8 & & .9 & \\
\hline & & & & & & & 6 & & 6.3 & & 7 & & 9.7 & 5 & \begin{tabular}{|l}
2.7 \\
\end{tabular} & .3 & 4 & 7 & 4 & .4 & 8 & .9 & & 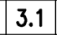 & \\
\hline & & & & & & & 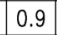 & & .7 & 6 & 0.0 & & 1 & 0 & 1.6 & .8 & 2 & 3 & 7 & & & .0 & & & \\
\hline & & & & & & & 6 & & 5.5 & 10.2 & 2.6 & 9.4 & 7.8 & & 0.3 & 3 & .5 & & 0 & & 5 & .1 & & & \\
\hline & & & & & & & 4 & & 1.2 & 0.1 & 3.4 & 1.9 & 13. & & 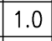 & .0 & 3 & 6 & 5 & 1.4 & 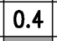 & .0 & & & \\
\hline & & & & & & & & & .6 & & 2 & 4 & 1 & & 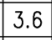 & & & 2 & 3.3 & 1.6 & 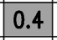 & & & & \\
\hline & & & & & & & H & & .7 & & 2 & & & & & & & .9 & .9 & 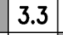 & & & & & \\
\hline & & & & & & & & & .5 & & .0 & & & & 2 & & 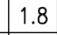 & 0 & 1.1 & 2.2 & 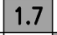 & & & & \\
\hline & & & & 1 & & & 2.2 & & 5.9 & & 5.4 & 1.5 & 26. & & 0.0 & 2.8 & 1.4 & .9 & 1.7 & .3 & 1.9 & .0 & & & \\
\hline & & & & & &. & 7.2 & & 6.1 & & 2.6 & 4.2 & 26. & 5 & 2.8 & 2.5 & 2.5 & .4 & 2.6 & .4 & .6 & .0 & & & \\
\hline & & & & 3 & 5 & 2 & 0.1 & .9 & 0.5 & & 3 & 1.2 & 13. & 4 & 3.4 & \begin{tabular}{|l}
4.4 \\
\end{tabular} & 4.6 & 7 & 2.5 & .7 & 3.5 & 0.1 & & .9 & \\
\hline & & & & .1 & 4 & 3 & 3.9 & 0.5 & 8.4 & & 3.4 & 3.4 & 26.6 & 4 & \begin{tabular}{|l|l|}
1.2 \\
\end{tabular} & 3.4 & 2.8 & 5 & 0.6 & .9 & .1 & .1 & & .9 & 2.0 \\
\hline & & 2 & & & & 4 & 3.9 & & 2.8 & & 0.1 & 10.0 & 24.1 & .1 & 3.3 & 3.0 & 4 & 8 & 4.8 & 4 & 1 & .6 & & & 0 \\
\hline & & 8 & & & & 1 & 3.6 & & 4.0 & & 5.1 & 0.9 & 1 & & 3.6 & 5.1 & 4 & 6 & 0.4 & 8 & 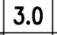 & .1 & & & \\
\hline & & & & & & 9 & 1 & & \begin{tabular}{|l|l|} 
\\
\end{tabular} & & 10.0 & 8.1 & 2 & & \begin{tabular}{|l} 
\\
\end{tabular} & & 9 & 4 & 0.7 & .9 & & .1 & & & \\
\hline & & & & & & & & & 2.3 & & 7 & 4 & 18 & & .5 & & & & & & & & & & \\
\hline & & & & & & & & & 8.3 & & & & 17. & & 2.0 & & & & & & & & & & \\
\hline & & & & & & & 2.8 & & 0.1 & & 0.1 & .2 & & & 2.2 & & .5 & & 0 & & & & & & \\
\hline & & & & & & & 8 & & 8.8 & & 0.8 & & 31. & & .4 & & .1 & & .1 & $t$ & & & & & \\
\hline & & & & & & & & & 1 & & .7 & 2.3 & 8. & & & 1.0 & 2 & & & 1.3 & & & & & \\
\hline & & & & 3 & & & 2.3 & & 4.6 & & .4 & 1.3 & 13 & & .9 & 4. & 9 & 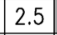 & 2.2 & 2.1 & & & & & \\
\hline & & & & & & & 4 & & 1.3 & & 7 & 2.8 & 21. & & 3.6 & 0.1 & 5 & 7 & 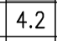 & 3.4 & & .8 & & & \\
\hline & & & & & & & 5 & & 9 & & & 1.9 & 6. & & 0.1 & .8 & 2.2 & & 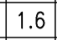 & 2.6 & & 3 & & & \\
\hline & & & & & & & 1.9 & & 3 & & 5 & 0.9 & 12. & & 1.3 & & 2.1 & & 2.4 & 2.4 & & .6 & & & \\
\hline & & & & & & & 4.1 & & 1.0 & & & 2.8 & 2 & & .7 & + & .4 & & 3.0 & 32 & & .2 & & & 2.3 \\
\hline & & & & & & & & & & & & & 2 & & 4 & & 2 & & & & & .0 & & & 2.6 \\
\hline & & & & & & & & & 4.7 & & & 8 & & & 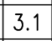 & & & & & & & .8 & & & \\
\hline & & & & & & & 6.9 & & & & & & & & 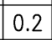 & & & & & 8 & & & & & \\
\hline & & & & & & & & & 11 & & & & & & & & & & & & & & & & \\
\hline & & & & & & & & & & & & & & & & & & & & & & .0 & & & \\
\hline & & & & & & & & & & & & & & & & & & & & & & & & & \\
\hline & & & & & & & & & $=$ & & & & 1 & & 7 & & 2 & & & 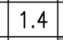 & & & & & \\
\hline & & & & & & & & & 2 & 2.4 & [1] & & 2 & & 6.1 & & & & & 1. & & .3 & & & \\
\hline & & & & & & & .9 & & .9 & 2.6 & 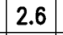 & & 11 & & 0.2 & & & & & & & & & & \\
\hline & & & & & & & .2 & & .8 & & 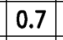 & 3.9 & 3. & & & & 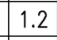 & & & & & & & & \\
\hline & & & & & & & ( & & y. & 0.8 & 1 & & 7.8 & & & & 2.7 & & & & & .1 & & & \\
\hline & & & & & & & & & 6 & 7.8 & 1 & & 18 & & & & 3.1 & & 0.7 & 1.0 & & .4 & 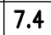 & & \\
\hline & & & & & & & & & 7 & & 3 & t & 78 & & .0 & 1 & .7 & 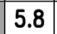 & 7.2 & & & 2.2 & & .7 & 4.1 \\
\hline & & & & & & & & & & & & & 2 & & 2.1 & & 3.5 & 2 & & 1 & & .5 & & & 1.4 \\
\hline & & & & & & & & & & & & & 3 & & 6 & & .0 & & & 8 & t & 3 & & & 2.9 \\
\hline & & & & & & & & & & & & & & & & & & & & & & .1 & & & \\
\hline & & & & & & & & & & & & & & & & & & & & & & & & & \\
\hline & & & & & & & & & & & & & & & & & & & & & & & & & \\
\hline & & & & & & & & & & & & & & & & & & & & & & & & & \\
\hline & & & & & & & & & 0 & & & & & & 3 & & & & & & & & & & \\
\hline & & & & & & & & & & & 4 & 4 & 17 & & 1.2 & & & & & & & & & & \\
\hline & & & & & & & & & & & & & 22 & & & 3 & 5 & & & $t$ & & 4 & & & \\
\hline & & & & & & & 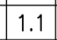 & & & & 0.8 & & & & & , & 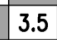 & & & & 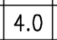 & & & & \\
\hline & & & & & & & & & & & & & 3 & & & & 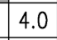 & & & & & & & & \\
\hline & & & & & & & 5.7 & & 2 & & 6 & & 2 & & & 3 & t & & 4.5 & .1 & 0.8 & 4 & & & .0 \\
\hline & & & & & & & .1 & 1 & & & & & 2 & & .1 & & 1 & & ti & 3.1 & 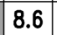 & 5.9 & & & 1.4 \\
\hline & & & & & & & & & & & & 3 & & & 2 & & 8 & & 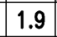 & .6 & 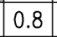 & .5 & & .0 & 1.8 \\
\hline & & & & & & & & & & & & & & & & & 1 & & & 3 & & .3 & & & \\
\hline & & 4 & 9 & & & & & & & & & 4.6 & & & & 7 & 0.8 & 4 & 1.1 & .4 & \begin{tabular}{|l|} 
\\
\end{tabular} & 2.1 & 2.4 & .9 & \\
\hline
\end{tabular}


vague-onset years, during which the cessation of the easterly regime was not immediately followed by a wellbuilt westerly regime. In summary, for about 1 out of every $5 \mathrm{yr}$, the SCS monsoon onset is somewhat ambiguous in terms of establishment of steady tropical westerlies, which presents a major challenge for objectively defining monsoon onset.

The most prominent feature of the SCSSM onset is a firm establishment of steady westerlies that is often accompanied by a sudden cessation of the easterlies or an abrupt acceleration of the westerlies (left panel of Table 1). These characteristics lead to the following objective criteria for defining the onset date.

The onset date of the SCSSM is defined by the first pentad after 25 April that satisfies the following two criteria: (a) in the onset pentad $U_{\mathrm{SCS}}>0$; (b) in the subsequent four pentads (including the onset pentad) $U_{\mathrm{SCS}}$ must be positive in at least three pentads and the accumulative four pentad mean $U_{\mathrm{SCS}}>1 \mathrm{~m} \mathrm{~s}^{-1}$.

As seen from Table 2, sudden acceleration of $U_{\text {SCS }}$ is a characteristic feature of the onset. Although the above definition did not explicitly require an abrupt change in westerly speed across the onset pentad, the resultant onset pentads indeed demonstrate a sharp increase in $U_{\mathrm{sCS}}$. The last row in the left panel of Table 2 shows that the increase in westerly speed across the onset pentad, which is defined by DU, that is, $U_{\text {SCS }}(1,2,3)$ minus $U_{\mathrm{SCS}}(-1,-2,-3)$, is greater than $7 \mathrm{~m} \mathrm{~s}^{-1}$, where $U_{\mathrm{SCS}}$ $(1,2,3)$ denotes the accumulative $U_{\mathrm{SCS}}$ for the consecutive three pentads including the onset pentad and $U_{\mathrm{SCS}}$ $(-1,-2,-3)$ denotes the accumulative $U_{\mathrm{SCS}}$ for the consecutive three pentads before the onset pentad.

Note also that before 25 April, the seasonal transition of large-scale circulation remains premature for the summer monsoon onset over the SCS; therefore, the occasional westerlies over the SCS are not of tropical origin and are excluded in the definition. More discussion on this point will be offered in section $5 \mathrm{~b}$.

The shaded boxes in the left panel of Table 2 show the onset pentads that are determined using the above definition. The earliest onset occurs in P25 (1-5 May), while the latest is at P34 (14-19 June). The maximum range is about 10 pentads (50 days).

\section{The commencement and salient phases of the broadscale East Asian summer monsoon}

\section{a. The seasonal transition}

The seasonal transition of the low-level monsoon circulation of the broadscale EASM can be objectively described using the dominant empirical orthogonal function (EOF) mode (EOF1), which accounts for about $34.7 \%$ of the total variance of $U_{850}$ over East Asia and the western North Pacific $\left(0^{\circ}-40^{\circ} \mathrm{N}, 100^{\circ}-140^{\circ} \mathrm{E}\right)$ for the period from P20 (6-10 April) to P37 (30 June-4 July). The spatial structure of EOF1 is characterized by the pronounced tropical westerly monsoon between $0^{\circ}$ (a) Spatial pattern of EOF1 (34.7\%)

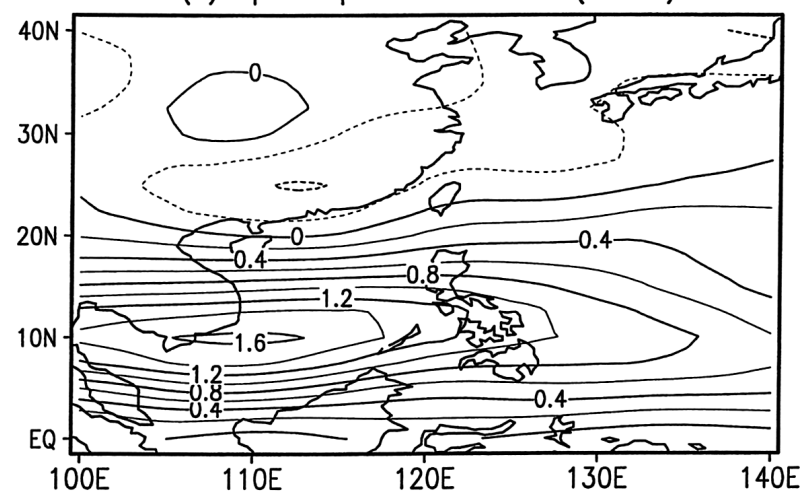

(b) Principal component of EOF1 (34.7\%)

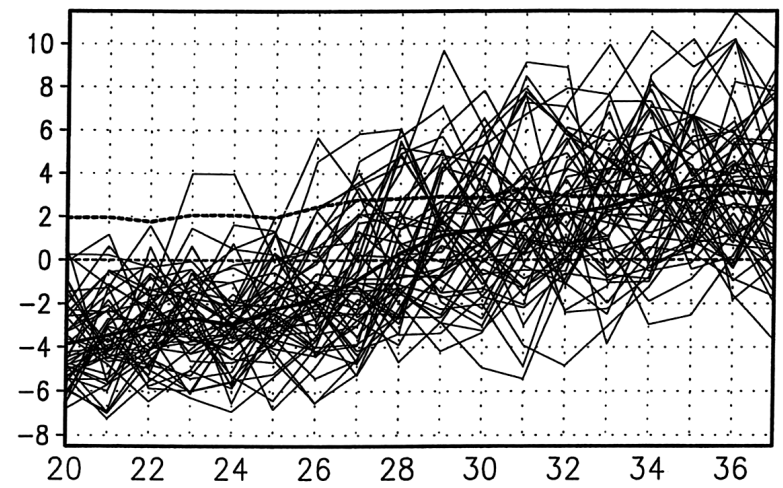

FIG. 3. (a) The spatial patterns of the first EOF mode of the 850$\mathrm{hPa}$ zonal wind in the domain $0^{\circ}-40^{\circ} \mathrm{N}, 100^{\circ}-140^{\circ} \mathrm{E}$. This EOF1 mode was derived using pentad mean 850-hPa zonal wind from P20 (6-10 Apr) to P37 (30 Jun-4 Jul) of each year from 1948 to 2002. (b) The principal components of the dominant EOF mode. The digitized time series of the principal components are shown in Table 2 (right panel). The thick line represents the climatological mean value of the principal component. The thick dashed line denotes the standard deviation.

and $20^{\circ} \mathrm{N}$ with its maximum axis along $10^{\circ} \mathrm{N}$ and centered in the western-central SCS (Fig. 3a). This spatial structure suggests that the establishment of the tropical westerlies over the SCS is an essential feature of the seasonal variation of the large-scale circulation over the East Asia-WNP region.

The principal component of the EOF1 mode, $U_{\mathrm{EOF} 1}$, represents the time evolution of the EASM low-level summer monsoon circulation. The time series of $U_{\mathrm{EOF} 1}$ for each year are tabulated in the right panel of Table 2 and plotted in Fig. 3b. The climatological mean $U_{\text {EOF1 }}$ (the thick line in Fig. 3b) increases gradually as the season progresses. It reverses sign (from negative to positive) on P28 (16-20 May). Obviously the climatological mean $U_{\mathrm{EOF} 1}$ represents the mean seasonal transition. The sign reversal on P28 indicates that the tropical $850-\mathrm{hPa}$ zonal wind component south of $20^{\circ} \mathrm{N}$, represented by the first EOF mode (Fig. 3a), rapidly changes from easterly to westerly. For each year, however, $U_{\mathrm{EOF} 1}$ contains not only the mean seasonal transition but 
also quite large intraseasonal variations on time scales of 4-10 pentads (right panel of Table 2 and Fig. $3 b$ ). This leads to the primary difficulty for defining the monsoon onset for an individual year.

Can $U_{\mathrm{EOF} 1}$ be used to determine the summer monsoon onset over the East Asia-WNP region? Inspection of Table 2 reveals, for the majority of the years examined, that $U_{\mathrm{EOF} 1}$ exhibits a noticeable shift from a negative (steady easterly) to a positive (steady westerly) regime. For these years, the onset pentad can be readily determined without ambiguity. For the other years during which strong intraseasonal variability exists or the switch of the regime is not evident, certain objective criteria are necessary for determining the onset date. With an adequate choice of the objective criteria, the first principal component, denoted by $U_{\mathrm{EOF} 1}$, can be used to define the onset of the broadscale EASM.

The onset of the broadscale EASM is defined as the first pentad after 25 April during which the $U_{\mathrm{EOF} 1}$ changes to a positive value from a negative value in the previous pentad, and in the consecutive four pentads (including the onset pentad) $U_{\mathrm{EOF} 1}$ must be greater than zero in at least three pentads. The shaded boxes in the right panel of Table 2 show the date of onset of the EASM determined using the above definition.

\section{b. Linkage between the SCSSM onset and the broadscale EASM commencement}

The local definition of the SCSSM onset turns out to be a characteristic of the seasonal transition of the largescale circulation over the broadscale EASM domain. This is supported by the fact that the local index for SCSSM, $U_{\mathrm{SCS}}$, and the large-scale index for the broadscale EASM, $U_{\mathrm{EOF} 1}$, are highly correlated (the correlation coefficient is 0.97 ). The strongest westerlies of the first EOF mode for the EA-WNP region are found between $5^{\circ}$ and $15^{\circ} \mathrm{N}$ and from $100^{\circ}$ to $120^{\circ} \mathrm{E}$ (Fig. 3a). This region overlaps the region where the local SCSSM index $U_{\mathrm{SCS}}$ is defined. It indicates that the $U_{\mathrm{SCS}}$ exemplifies the principal mode of the low-level monsoon circulation over East Asia and the neighboring WNP.

The climatological mean onset of the EASM as signified by $U_{\mathrm{EOF} 1}$ concurs precisely with the climatological mean SCSSM onset date shown in Fig. 1. The onset dates for SCSSM, which is defined using $U_{\mathrm{SCS}}$, are nearly the same as those of the EASM onset dates defined by the use of $U_{\mathrm{EOF} 1}$ except for 1968, during which the differences are greater than two pentads (Fig. 4 and Table 2). The consistency between the onset over the SCS and large-scale East Asia-WNP domain indicates that the onset of the summer monsoon over the SCS signifies the beginning of the summer monsoon over East Asia.

\section{c. Two-stage onset of the broadscale East Asian summer monsoon}

The EASM onset starts in the SCS and moves progressively northward. Most Chinese meteorologists be-

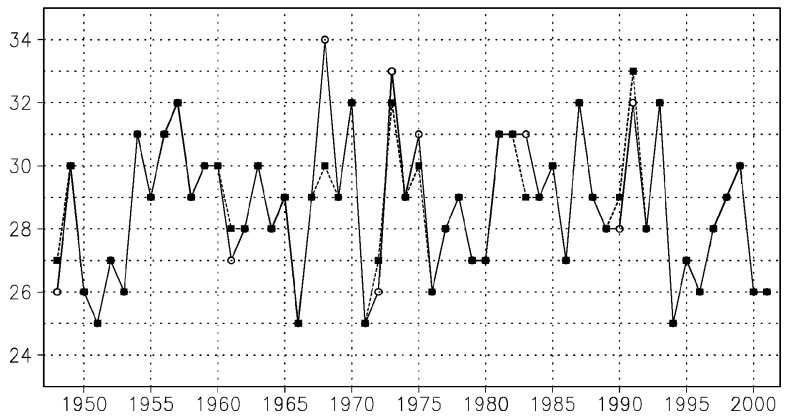

FIG. 4. Time series of the onset date defined for the SCSSM using $U_{\mathrm{SCS}}$ (solid) and for the EASM using $U_{\mathrm{EOF} 1}$ (dashed).

lieve that the migration of the subtropical monsoon front is stepwise (Ding 1991). In particular the quasi-stationary rainbelt associated with the subtropical monsoon front tends to stagnate over the Yangtze River and Huai River basin from mid-June to mid-July, which is referred to as the mei-yu in China or the baiu in Japan.

To examine the progression of the EASM, we performed a multivariable EOF analysis of the $850-\mathrm{hPa}$ zonal and meridional winds and rainfall from 6 April to 9 July for the period 1979-2001. The first three EOF patterns and corresponding principal components are shown in Fig. 5. The climatological mean principal component (Fig. 5b) resembles the $U_{\mathrm{EOF} 1}$ of the $850-\mathrm{hPa}$ zonal wind (Fig. 3b) with a notable difference. The principal component of the multivariate EOF1 not only shows the slow seasonal transition (increasing trend) but also exhibits two rapid transition periods. One occurs from P26 to P28 and the other from P33 to P35. The former means the SCSSM onset while the later indicates the onset of the mei-yu. This result suggests that the onset of the SCSSM and mei-yu are two salient phases in the progression of the broadscale EASM.

The two-stage onset of the broadscale EASM is also supported by the results shown in Fig. 1. It is seen that two rapid transitions, in both zonal wind and rainfall, are evident over the SCS: one from P26 to P28 (16-20 May) and another from P32 to P34 (14-19 June). The second transition coincides with a sudden northward expansion of heavy rainfall (as signified by the contour of the $8 \mathrm{~mm} \mathrm{day}^{-1}$ precipitation rate).

This second-stage onset of the EASM is also represented by the second EOF mode. The physical interpretation of the second and third EOF modes must be made with caution because the EOF analysis does not necessarily produce physically meaningful modes. Regardless of that possible caveat, the structure of EOF2 indeed shows the rainbelt located in the normal mei-yu or baiu front and this pattern occurs on average around P33 (10-14 June), which agrees very well with the mean onset date of the mei-yu (Chen et al. 1992). The third EOF mode can be interpreted as representing the premei-yu period, which peaks from P30 to P33 and the major rainbelt is found over southeast China, northern 
(a)
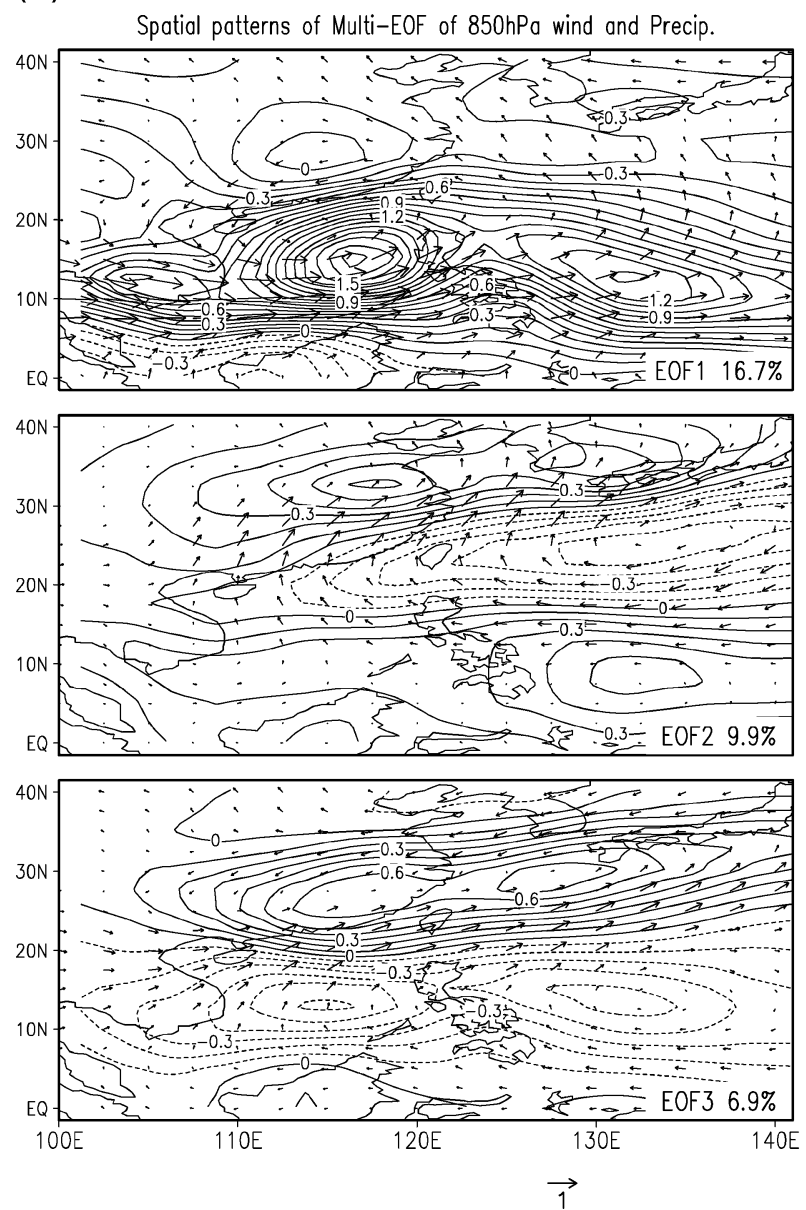

(b) Principal component of Multi-EOF of $850 \mathrm{hPa}$ wind and Precip.
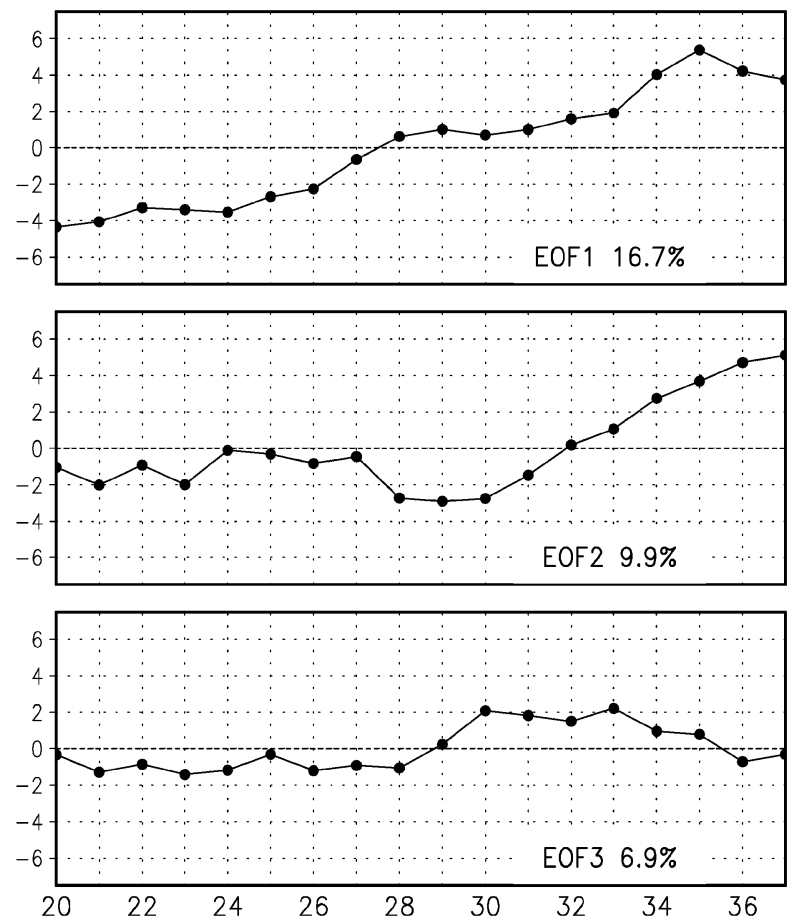

FIG. 5. (a) Spatial structures and (b) climatological mean principal components of the first three multivariate EOF modes derived from pentad mean departures of the 850-hPa zonal and meridional winds and CMAP (rainfall) from P20 (6-10 Apr) to P37 (30 Jun-4 Jul) of each year for the period 1979-2001. The contours in (a) represent precipitation rate with units of $\mathrm{mm} \mathrm{day}^{-1}$.

Taiwan, Okinawa, and southern Kyushu (Chen 1994). Note, however, that the first three EOFs together describe the progressive northward migration of the mean EASM front and rain belt.

In summary, the $U_{\mathrm{EOF}}$ signifies the large-scale seasonal transition and the first-stage onset of the broadscale EASM. The multivariate (both $U_{850}$ and rainfall) EOF1 shows a signal of the mei-yu onset (the second stage of onset) (Fig. 5b). The second stage of the EASM onset is also represented by the second EOF mode. The first three EOFs together describe the progressive northward migration of the EASM front and associated rainbelt.

\section{Concluding remarks}

\section{a. Conclusions}

The mean summer monsoon onset over the South China Sea (SCS) is abrupt; yet defining the onset date for individual years has been difficult and controversial.
A generally accepted definition is imperative for investigating the interannual variability of the SCS summer monsoon.

Based on the notion that the SCSSM is a tropical monsoon and the establishment of the tropical southwesterly monsoon is an essential feature of the monsoon onset, we propose to use a single variable that provides succinct and objective criteria for defining the summer monsoon onset over the South China Sea. The SCSSM onset is defined by using $U_{\mathrm{SCS}}$, that is, the 850 -hPa zonal winds averaged over $5^{\circ}-15^{\circ} \mathrm{N}, 110^{\circ}-120^{\circ} \mathrm{E}$. This local index depicts not only the sudden establishment of the monsoon southwesterlies in the SCS, but also the onset of the rainy season in the central-northern SCS (Fig. 2).

We consider that the broadscale East Asian summer monsoon (EASM) covers a broad region of East Asia and the adjacent WNP, from $0^{\circ}$ to $40^{\circ} \mathrm{N}$ and from $100^{\circ}$ to $140^{\circ} \mathrm{E}$. We recognize that the large-scale seasonal transition of EASM can be described by the principal component of the dominant EOF of the $850-\mathrm{hPa}$ zonal 
wind in the above domain. It is found that the local index $U_{\mathrm{SCS}}$ represents very well the dominant mode of the EASM (as represented by the $850-\mathrm{hPa}$ zonal wind), indicating that the SCSSM onset signifies the onset of the entire broadscale EASM.

It is further shown that the onset of the broadscale EASM consists primarily of two phases. The SCSSM onset is the first while the start of the mei-yu or baiu period is the second phase. The broadscale EASM onset is a characteristic two-stage onset. The SCS onset manifests itself as a spectacular event that signifies the commencement of the eastern part of the Asian summer monsoon. This event is particularly crucial since it represents the first time that the monsoon-scale southwestern flow is able to penetrate the SCS and to connect the tropical westerlies and the subtropical westerlies (and subtropical front) to the north of the subtropical high. Before this event, the western Pacific subtropical ridge, which blocks the tropical monsoon flow into southeastern China, controls the SCS and the subtropical front is detached from the tropical southwesterlies. During the second phase, the onset of the mei-yu season, the westerly monsoon exhibits another surge over the SCS.

\section{b. Discussion}

There are issues concerning the definition that deserve further clarification.

Why can the complex monsoon onset over the SCS be determined by using a single variable, $U_{\mathrm{Sc}}$, for the central SCS zonal winds? The SCSSM is a tropical monsoon. The establishment of a tropical westerly regime over the central SCS is an essential feature of the onset (Wang and Wu 1997; Xie et al. 1998; Lin et al. 2000; Chen et al. 2001). The index $U_{\mathrm{SCS}}$ captures the essence of the tropical monsoon onset in the SCS. Using this index, a vague monsoon onset occurs in only about $20 \%$ of the total records. While a great variety of meteorological variables have been considered for defining the SCSSM onset, none of them has demonstrated better skill for defining the onset than $U_{\mathrm{SCS}}$. While some have concluded that multivariables are necessary for depicting SCSSM onset (e.g., Qian and Yang 2000), we demonstrate that this matter can be simplified considerably, and that the onset can be effectively determined using a single variable.

Some previous studies reported failures in their attempts to define SCSSM onset using westerly index (e.g., Zhu et al. 2001). These failures arise from the improper choice of the latitudinal domain for the westerly index. As shown in Fig. 1a, the zonal flow north of $17^{\circ} \mathrm{N}$ does not change direction during the mean monsoon onset. Therefore, the westerlies in the northern SCS cannot be used as an indication of the tropical monsoon. The northern SCS is open to the invasion of a cold front from the north. The westerly flow occurring before the onset is located north of the subtropical ridge and is not of tropical origin. Therefore, it is important to exclude the westerlies north of $17^{\circ} \mathrm{N}$ when defining the tropical monsoon burst over the SCS.

The late April false alarm onset is another source of confusion in determining the onset date. Typical examples of bogus onset occurred in 1974, 1975, 1984, 1985 , and 1999, during which a two-three-pentad-long westerly regime occurred in late April (Table 2). These westerly episodes, which may last two-three pentads and are accompanied by heavy rainfall, are not tropical southwesterly monsoons. A firm establishment of the tropical southwesterly monsoon requires the (a) attendance of a large-scale seasonal transition and (b) connection of the SCS southwesterlies with the southwesterlies over the northern Indian Ocean; both typically occur after late April. The late April westerly intermission over the SCS is often followed by a prolonged easterly regime (Table 2) and is not a bona fide summer monsoon onset. This is the reason that we specify the onset pentad to be after 25 April in our criteria.

A phenomenon associated with the bogus onset is that the northern SCS (north of $17^{\circ} \mathrm{N}$ ) rainy season often starts locally before the onset of the SCSSM. The most plainly evident examples are found in 1984, 1985, and 1999 during which a three-pentad intense rainy period occurred in late April. Similar to the bogus westerly episodes, these wet periods are primarily caused by disturbances in the subtropical front or intermittent tropical cyclone activities. They were not regarded as signs of monsoon outbreak over the SCS (Qian and Yang 2000 $\mathrm{Li}$ and Wu 2000; Chen et al. 2001). In these scenarios, the central and southern SCS remain under the control of the western Pacific subtropical ridge. This pattern is often seen during the vague SCSSM onset. Therefore, the start of the rainy season over the northernmost part of the SCS does not necessarily represent the onset of the tropical SCSSM. The above statement does not mean that the northernmost part of the SCS is not important or can be ignored. A mixture of the subtropical and tropical monsoons complicates the conditions in that region. Simply looking at rainfall would not help in identifying the onset of the tropical monsoon over the SCS.

Another factor that complicates the determination of the onset date is the intraseasonal oscillation. Previous studies have noted the effects of the intraseasonal oscillation on the SCSSM, including its onset process (Chen and Chen 1995; Wu et al. 1999). This ambiguity, caused by the intraseasonal oscillation, is minimized by the proposed objective criteria for assessing the steadiness of the tropical westerlies. While the proposed criteria appear to be objective and insensitive to slight changes in the criteria, they are nevertheless determined empirically based on data analysis.

Note that the high correlation between $U_{\mathrm{SCS}}$ and $U_{\mathrm{EOF}}$ does not mean that they are physically alike or that they can be used to replace each other. In fact, each index has its own meteorological meanings. Because $U_{\mathrm{EOF} 1}$ and 
$U_{\text {SCS }}$ describe the large-scale and local features, respectively, one should not expect that they will always give an identical onset date, for example, 1968. The discrepancy in 1968 suggests that the onset over the SCS, while it is an excellent indicator of EASM onset, does not always represent the onset of the broadscale EASM onset because of its localized character. Additional data or tools are needed for some years to determine the first phase of the large-scale onset of the EASM. From a practical point of view $U_{\mathrm{SCS}}$ is more useful than $U_{\mathrm{EOF} 1}$ for defining the EASM onset. Obtaining $U_{\mathrm{EOF} 1}$ time series requires data up to $10 \mathrm{July,}$ while when using $U_{\mathrm{SCS}}$ the onset can be judged shortly after the establishment of steady westerlies over the central SCS.

Acknowledgments. NSF Award ATM00-70230 and the NOAA CLIVAR/Pacific program have supported the first author during this work. The first and third authors acknowledge support from the International Pacific Research Center (IPRC, which is sponsored in part by the Frontier Research System for Global Change). The second author is supported by NSC 90-2111-M-002-031AP7.

\section{REFERENCES}

Ananthakrishnan, R., and M. K. Soman, 1988: The onset of the southwest monsoon over Kerala: 1901-1980. J. Climatol., 8, 283296.

Chang, C.-P., and T.-C. Chen, 1995: Tropical circulations associated with southwest monsoon onset and westerly surges over the South China Sea. Mon. Wea. Rev., 123, 3254-3267.

Chen, G. T. J., 1994: Large-scale circulations associated with the East Asian summer monsoon and the Mei-Yu over South China and Taiwan. J. Meteor. Soc. Japan, 72, 959-983.

Chen, L., M. Dong, and Y. Shao, 1992: The characteristics of interannual variations on the East Asian monsoon. J. Meteor. Soc. Japan, 70, 397-421.

— , Y. Song, and M. Murakami, 1996: The characteristics of convective system change during the onset period of summer monsoon. New Advance of the Asian Monsoon Study (in Chinese), J. He et al. Eds., China Meteorological Press, 54-65.

- W. Li, P. Zhao, and R. Tao, 2001: On the process of summer monsoon onset over East Asia. Acta Meteor. Sin., 15, 436-449.

Chen, T.-C., and J.-M. Chen, 1995: An observational study of the South China Sea monsoon during the 1979 summer: Onset and life cycle. Mon. Wea. Rev., 123, 2295-2318.

Ding, Y., 1991: Advanced Synoptic Meteorology. China Meteorological Press, 792 pp.

Gao, H., J. He, Y. Tan, and J. Liu, 2001: Definition of 40-year onset date of South China Sea Summer Monsoon. J. Nanjing Inst. Meteor., 24, 379-383.

He, H., Z. Wen, and M. Jian, 2001: The climatological characteristics of the onset timing of the South China Sea tropical monsoon in the recent 50 years. Determination of the Onset Date of the South China Sea Monsoon and the Monsoon Index (in Chinese), J. He et al., Eds., China Meteorological Press, 49-54.

He, J., Q. Zhu, and M. Murakami, 1996: T BB data revealed features of Asian-Australian monsoon seasonal transition and Asian summer monsoon establishment. J. Trop. Meteor., 12, 34-42.

Hsu, H.-H., C.-T. Terng, and C.-T. Chen, 1999: Evolution of largescale circulation and heating during the first transition of Asian summer monsoon. J. Climate, 12, 793-810.

Hwu, J.-W., M.-S. Chen, and J.-T. Wang, 1998: A preliminary analysis of the effects of mid-latitude and tropical systems on the onset of South China Sea summer monsoon. Proc. 15th Conf. on Weather Analysis and Forecast, Taipei, Taiwan, Central Weather Bureau, 389-393.

Kalnay, E., and Coauthors, 1996: The NCEP/NCAR 40-Year Reanalysis Project. Bull. Amer. Meteor. Soc., 77, 437-471.

Kueh, M.-T., and S.-C. Lin, 2001: South China Sea summer monsoononset definition and characteristics. Atmos. Sci., 29, 141-170.

Lau, K.-M., and S. Yang, 1997: Climatology and interannual variability of the Southeast Asian summer monsoon. Adv. Atmos. Sci., 14, 141-162.

Li, C., and J. Wu, 2000: On the onset of the South China Sea summer monsoon in 1998. Adv. Atmos. Sci., 17, 193-204.

Liang, J., S. Wu, and J. You, 1999: The research on variations of onset time of the SCS summer monsoon. J. Trop. Meteor., 15, 97-105.

Lin, P.-H., and H. Lin, 1997: The Asian summer monsoon and MeiYu front. Part I: Cloud patterns as a monsoon index. Atmos. Sci., 25, 267-287.

Lin, S.-C., R.-J. May, and M.-C. Yen, 2000: A composite study of the atmospheric circulation and water vapor transport during the onset of South China Sea summer monsoon. Atmos. Sci., 28, 281-292.

LinHo, and B. Wang, 2002: The time-space structure of the AsianPacific summer monsoon: A fast annual cycle view. J. Climate, 15, 2001-2019.

Lu, E., and J. C. L. Chan, 1999: A unified monsoon index for South China. J. Climate, 12, 2375-2385.

Lu, M.-M., Y.-L. Chen, and M.-S. Chen, 2000: Interannual variability of the onset timing of the South China Sea summer monsoon and its possible mechanism. Preprints, 24th Conf. on Hurricanes and Tropical Meteorology, Fort Lauderdale, FL, Amer. Meteor. Soc., 581-582.

May, R.-J., 1997: A composite study of the South China Sea summer monsoon. M.S. dissertation, Dept. of Atmospheric Sciences, National Central University, Chung-Li, Taiwan, 98 pp.

Qian, W., and S. Yang, 2000: Onset of the regional monsoon over Southeast Asia. Meteor. Atmos. Phys., 75, 29-38.

Soman, M. K., and K. K. Kumar, 1993: Space-time evolution of meteorological features associated with the onset of Indian summer monsoon. Mon. Wea. Rev., 121, 1177-1194.

Tanaka, M., 1992: Intraseasonal oscillation and the onset and retreat dates of the summer monsoon over East, Southeast Asia and the western Pacific region using GMS high cloud amount data. $J$. Meteor. Soc. Japan, 70, 613-629.

Tao, S., S. He, and Z. Yang, 1983: Observational study on the onset of the summer monsoon over eastern Asia in 1979. Sci. Atmos. Sin., 7, 347-355.

Tao, S.-Y., and L.-X. Chen, 1987: Review of recent research on the East Asian summer monsoon in China. Monsoon Meteorology, C.-P. Chang and T. N. Krishnamurti, Eds., Oxford University Press, 60-92.

Wang, B., 1994: On the annual cycle in the tropical eastern-central Pacific. J. Climate, 7, 1926-1942.

_ 1995: Interdecadal changes in El Niño onset in the last four decades. J. Climate, 8, 267-258.

- and LinHo, 2002: Rainy seasons of the Asian-Pacific monsoon. J. Climate, 15, 386-398.

_- and R. Wu, 1997: Peculiar temporal structure of the South China Sea Summer monsoon. Adv. Atmos. Sci., 14, 177-194.

__ , and X. Xu, 1997: Northern Hemisphere summer monsoon singularities and climatological intraseasonal oscillation. J. Climate, 10, 1071-1085.

Wang, S., and Y. Qian, 2000: Diagnostic study of apparent heat sources and moisture sinks in the South China Sea and its adjacent areas during the onset of 1998 SCS monsoon. Adv. Atmos. Sci., 17, 285-298.

Wu, G., and Y. Zhang, 1998: Tibetan Plateau forcing and the timing of the monsoon onset over South Asia and the South China Sea. Mon. Wea. Rev., 126, 913-927. 
Wu, M. L., S. Schubert, and N. E. Huang, 1999: The development of the South Asian summer monsoon and the intraseasonal oscillation. J. Climate, 12, 2054-2513.

Wu, R., and B. Wang, 2001: Multi-stage onset of summer monsoon over the western North Pacific. Climate Dyn., 17, 277-289.

Xie, A., Y.-S. Chung, X. Liu, and Q. Ye, 1998: The interannual variations of the summer monsoon onset over the South China Sea. Theor. Appl. Climatol., 59, 201-213.

Xie, P., and P. Arkin, 1997: Global precipitation: A 17-year monthly analysis based on gauge observations, satellite estimates, and numerical model outputs. Bull. Amer. Meteor. Soc., 78, 25392558.

Xu, H., J. He, and B. Zhou, 2001: Composite analysis of summer monsoon onset process over South China Sea. J. Trop. Meteor., 17, 10-22.
Yan, J., 1997: Observational study on the onset of the South China Sea southwest monsoon. Adv. Atmos. Sci., 14, 277-287.

Zhang, R., A. Sumi, and M. Kimoto, 1996: Impact of El Niño on the east Asian monsoon: A diagnostic study of the '86/87 and '91/ 92 events. J. Meteor. Soc. Japan, 74, 49-62.

Zhang, X., J. Li, Y. Ding, and J. Yan, 2001: A study of circulation characteristics and index of South China Sea summer monsoon. Acta Meteor. Sin., 15, 450-464.

Zhou, B., J. He, G. Wu, and G. Han, 2001: Discussion on the choice of the East Asian subtropical monsoon indices. Determination of the Onset Date of the South China Sea Monsoon and the Monsoon Index (in Chinese), J. He et al., Eds., China Meteorological Press, 111-117.

Zhu, Y., Y. Li, and W. Qian, 2001: Comparison of the SCS summer monsoon onset, characteristics derived from different datasets. J. Trop. Meteor., 17, 34-44. 